\title{
Asbestos and Its Alternatives
}

The ancients marveled at a type of exotic cloth, woven from rock fibers, that would not burn. Asbestos, from the Greek word meaning (ironically) "inextinguishable," is a group of natural hydrated mineral silicates that occur in fibrous form; these fibers resist high temperatures and offer high tensile strength and great chemical resistance. Over 3,000 uses have been recorded for asbestos fibers, including fire-resistant fabrics and papers, brake linings, flooring and roofing products, thermal insulating materials, filtration packs, and heat shields. Because of the known health hazards of asbestos fibers, alternative materials that share many of the same characteristics have been developed.

Thousands of years ago, people considered asbestos to have magical properties because of its ability to impart fire resistance to cloth into which it had been woven. In the first century A.D., Pliny the Elder described shrouds of woven asbestoscalled linum vivum, or "the funeral dress of kings"-used during cremations of the nobility. A century later, in his Tour of Greece, Pausanias described a lamp wick never consumed by flames. He called the material "Carpasian linen," a cloth made of mineral fiber extracted from Carpasius, a district of Cyprus. About the same time, Plutarch also recorded "perpetual lamp wicks" used in the temples of the vestal virgins.

In eighth century Europe, Charlemagne amazed several important guests with a fabulous tablecloth he could clean by tossing into a raging fire. When Marco Polo returned from Siberia in the 13th century, he told of a strange cloth that could be put directly into a fire and withdrawn unharmed and white as snow.

Asbestos remained a rare oddity until about 1868, when the first commercial asbestos mining operation began in the Italian Alps. The mineralogical term "asbestos" was first applied at this time to describe the specific fibrous amphibole mineral occurring in the Italian mine. Large-scale asbestos production began a few years later with the discovery of asbestos in Quebec, Canada.

Major mining of asbestos first began in Quebec in 1878, then in the Ural Mountains in Russia in 1885; 20 years later, South African asbestos mines opened up. The use of asbestos grew slowly during the first decades of the 20th century, but increased steadily after about 1930 . Total worldwide consumption in that year was 338,783 metric tons; in 1950 it had risen to 1.2 million tons after much prospecting for new asbestos deposits. Recently, annual worldwide production has reached about 5 million tons.

Today, six major types of asbestos are in use, the most common of which is called chrysotile asbestos. Chrysotile is the fibrous form of the mineral serpentine, a hydrous magnesium silicate (see photograph). A product of metamorphism, chrysotile is also found in limestone in contact with semi-intrusions of igneous rock. The individual fibers appear white, though the color of the aggregate in the veins ranges from amber to greenish. Under magnification, each fiber is composed of numerous fine threads crowded together. The individual fibers range in length from 0.16 to $3.8 \mathrm{~cm}$ in most places to all the way up to $30 \mathrm{~cm}$.

The major uses for asbestos fibers come chiefly from their ability to withstand high temperatures. Asbestos can withstand exposure to superheated steam and hightemperature industrial environments. Though the fibers become progressively

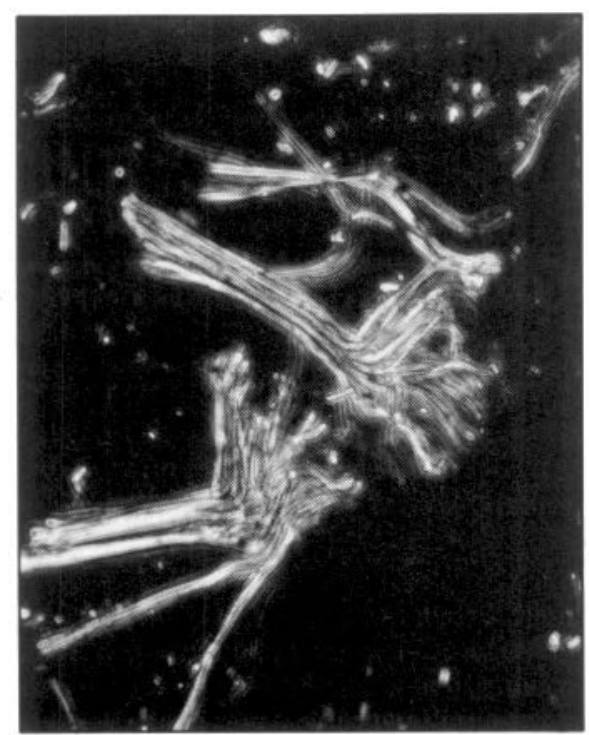

Fibers (magnification $128 x$ ) of chrysotile asbestos, the most common of the six major types of asbestos. Each fiber is composed of numerous fine threads that are usually 0.16 to $3.8 \mathrm{~cm}$ long but can range up to $30 \mathrm{~cm}$ long. Chrysotile is the fibrous form of the mineral serpentine, a hydrous magnesium silicate. (Photo courtesy of Lawrence Livermore National Laboratory) more brittle at temperatures above $400^{\circ} \mathrm{C}$, some asbestos products have specified working temperatures as high as $600^{\circ} \mathrm{C}$. The tensile strength increases slightly before diminishing rapidly between 300 $500^{\circ} \mathrm{C}$, as the crystalline structure begins to degrade.

Asbestos is also useful because of its fiber strength and chemical resistance. The tensile strength of asbestos fibers equals that of some grades of steel $(80,000$ to 100,000 pounds per square inch). Chemically, asbestos resists both acids and alkalis and also biological attack; this makes asbestos materials invaluable in hostile industrial environments.

The silky, flexible fibers can easily be spun into thread for textiles. Asbestos fibers are so fine that 10 kilometers of thread would weigh only about half a kilogram. Long fibers can be carded and spun into yarns. Smooth-surfaced asbestos fibers are often mixed with a rough-surfaced fiber, such as cotton, usually in $10-25 \%$ blends. These mixtures can be woven into various fabrics with a range of weights, thicknesses, and densities for specific uses. Asbestos fibers cannot be dyed easily, though, and the fibers have poor colorfastness.

In addition to chrysotile asbestos (mined mainly in Canada, Arizona, Russia, and Zimbabwe), the other forms include amosite (a brittle grayish-brown fiber found in South Africa), crocidolite or blue asbestos (found in South Africa, Bolivia, and Australia), and anthophyllite (a brittle white fiber found in Africa and Finland).

Chrysotile asbestos is usually extracted from open-pit mines. The fiber inclusions occur in small cracks throughout the massive rock, and thus are difficult to extract. The ore is first blasted loose, then the fibers are freed by crushing the parent rock; the larger seams (those about a centimeter wide) are selected out from the rubble, and the adhering rock is removed with a pick. The resulting chunks of ore may contain up to $30 \%$ water and must first be dried before the asbestos can be separated into fibers. The dried chunks then pass through a series of shaking screens, additional crushers, and an airstream that sucks away loosened fibers. To produce a single ton of asbestos fiber, the large Quebec mine handles 16 tons of ore, 8 tons of waste rock, and 23 tons of overburden.

The crude asbestos is then graded according to fiber length, tensile strength, flexibility, fineness, and infusibility. The longest fibers are carded and spun into 
threads; the smallest fibers are mixed with rock dust to make asbestos cement.

The mining and use of asbestos materials has always been connected with sickness among workers. In the first century A.D., Finey the Younger noticed illness in the slaves who first worked with asbestos. But since asbestos was not used in commercial quantities until the 19th century, the number of affected people remained insignificant. Within 20 years of the first factory production, the public health hazards began to be noticed. Between 1890 and 1895 in France, 16 out of the 17 workers in an asbestos-weaving factory died; within four more years, 11 men from an asbestos-spinning factory in England died by the age of 30 .

In 1906, some of these deaths were brought to the attention of the United Kingdom's Departmental Committee for Compensation for Industrial Diseasesthese are the first recorded cases of the disease diagnosed as "asbestọis." Not until
20 years later, though, did the first complete description of asbestosis appear, described as a disease resulting from the inhalation of small particles of asbestos dust. Asbestos fibers deposited in the lungs produce scar tissue (fibrosis) that leads to fatigue and breathlessness after longer exposure. Cancer and mesothelioma (a form of lung cancer) have also been associated with exposure to asbestos dust.

Increasing concern with the health effects of asbestos led to its restrictive use in the mid-20th century. Efforts to find synthetics and substitutes for asbestos intensified after 1950. Some of the more successful alternatives for fire protection include heat-resistant nylon fibers (such as Dupont's Nomex), special wood blends, bleached Teflon fluorocarbon fibers (used for the Apollo astronauts' suits and for missile fuel handling), and a sandwich of ceramic fibers between glass cloth. Glass fibers and mineral wool are used for thermal insulation, as well as vermiculite bonded with a high-alumina cement (which can withstand temperatures up to $1100^{\circ} \mathrm{C}$ ).

Other uses for asbestos include electric insulation, which can also be done with glass fabrics, thermosetting materials such as polyimide and polyethersulphone, and ceramic-fiber cloths. Bulk filters that normally use asbestos fibers can also use vermiculite or Teflon fluorocarbon fibers (especially in extreme temperatures or corrosive chemical environments). Some expensive alkali-resistant glass fibers have been added to concrete to replace asbestos cement.

New alternatives are being investigated for dry bearings, gaskets, jointings, and high-temperature caulking or door seals (such as kiln or furnace doors), that still require asbestos. Asbestos materials, once a marvel and now a health hazard, will likely be replaced in most types of manufacturing within the next decade or so.

KEVIN J. ANDERSON

\section{Train your entire organization in either of these timely and critical areas for a few thousand dollars:}

\section{Hazardous Waste Management}

More than seventy experts from backgrounds including national laboratories, universities, industry and law bring you the latest research, new technology, and practical applications in this live series of eleven programs.

Sponsored by WERC-A consortium of 2 national labs and 3 universities

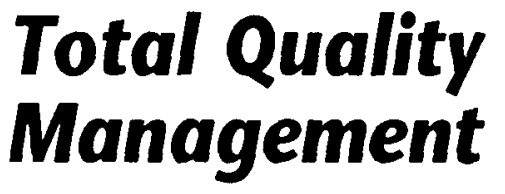

$T Q M$ means creating excellence in every single facet of your business. How to make this kind of operation work? That's what our experienced management experts help you accomplish in this interactive series.

Sponsored by University of New Mexico

\section{Get the latest management tools without the expense of travel by using these live videoconference training series!}

For information and registration material, call Connie Callan at 505-277-7750. 